\title{
AESTHETIC MANAGEMENT OF FRACTURED ANTERIORS- A CONSERVATIVE APPROACH
}

\author{
Rupankar Dey¹, Priti D. Desai², Paromita Mazumdar³, Laboni Ghorai ${ }^{4}$
}

1Postgraduate Student, Department of Conservative Dentistry and Endodontics, Gurunanak Institute of Dental Sciences and Research, Kolkata, West Bengal, India.

2Professor, Department of Conservative Dentistry and Endodontics, Gurunanak Institute of Dental Sciences and Research, Kolkata, West Bengal, India.

3Professor and HOD, Department of Conservative Dentistry and Endodontics, Gurunanak Institute of Dental Sciences and Research, Kolkata, West Bengal, India.

${ }^{4}$ Senior Consultant, Department of Oral Medicine \& Radiology, Avinash Dental Laboratories and Research Institute Pvt., Ltd., Kolkata, West Bengal, India.

HOW TO CITE THIS ARTICLE: Dey R, Desai PD, Mazumdar P, et al. Aesthetic management of fractured anteriors- a conservative approach. J. Evolution Med. Dent. Sci. 2018;7(35):3923-3925, DOI: 10.14260/jemds/2018/877

\section{PRESENTATION OF CASE}

Traumatic dental injuries are a common occurrence in routine dental practice. Such injuries mostly involve the anterior teeth, especially the maxillary incisors because of their vulnerable position in the dental $\operatorname{arch}^{1}$ and protrusion caused by the eruptive pattern. ${ }^{2}$ Though dental injuries usually affect a single tooth; however, road traffic accidents and sports injuries involve multiple tooth injuries. ${ }^{1}$ These traumatised anterior teeth require quick functional and aesthetic repair. ${ }^{3}$ However, aesthetic restoration of lost dental tissues of anterior teeth is a crucial challenge in restorative dentistry. Creating more conservative as well as functional and economical restorations simulating natural dental tissues is the main objective of up-to-date contemporary dentistry. ${ }^{4}$ Several factors that influence the management of coronal tooth fractures include extent of fracture, restorability of fractured tooth, soft tissue status, presence/ absence of fractured tooth fragment and its condition for use, occlusion, aesthetics, finances and prognosis. ${ }^{5-7}$ In case of anterior crown fracture involving noncomplicated enamel and dentin, minimal invasive and less time-consuming treatment options such as direct composite resin restorations compared to indirect ceramic restorations for the anterior dental aesthetics are preferred. ${ }^{8}$ However, one of the main challenges in anterior composite restorations is in establishing and reproducing the proper contour and contact form. 'Index Technique' using matrix system is a vital step in achieving this objective. Various matrices are available for anterior composite restorations, which can be broadly classified into flexible and rigid types. The more popular and widely used matrices are the Mylar strips (Flexible) and the Putty index (Rigid). ${ }^{9}$

This paper reports a case of non-complicated crown fractures due to dental trauma on maxillary right and left central incisors, treated with minimally invasive direct composite resin restorations by using Index Technique in a single appointment.

'Financial or Other Competing Interest': None.

Submission 15-07-2018, Peer Review 10-08-2018,

Acceptance 18-08-2018, Published 27-08-2018.

Corresponding Author:

Dr. Laboni Ghorai,

\#2, Hospital Dey Para Road,

Kolkata-700146, West Bengal, India.

E-mail: dr.labonidey@gmail.com

DOI: $10.14260 /$ jemds $/ 2018 / 877$

(c) (i) $\ominus$

\section{CASE REPORT}

A 21-year-old male patient was referred to the Department of Conservative Dentistry and Endodontics for the treatment of fractured upper front teeth. The patient reported a history of trauma 6 months back due to fall from a bicycle and presently had no pain or any other symptoms. Patient's medical history was non-contributory. Clinical examination revealed Ellis class II (uncomplicated) fracture irt 11 and 21 [Figure 1(a)]. The periodontal tissues were healthy and oral hygiene was in good condition. The regional lymph nodes were non-palpable. Chair-side examination revealed positive response irt 11 and 21 on electric pulp testing. Intraoral periapical radiograph confirmed the absence of pulpal or periapical pathosis [Figure 1(b)]. The patient's age and the examinations were both taken into consideration and restoration of fractured segments with direct composite resin restorations using Index Technique was considered as the treatment plan.

A pre-operative photograph was taken from the labial view by using a professional camera and documented. The restorative procedure commenced with the procedure of shade selection using composite shade samples known as the 'Button Technique.' Then, primary impression of the upper and lower arches were made using fast setting alginate (Algitex; DPI, Mumbai, India) and dental stone study models were prepared. Composite mock-up of the lost tooth structure was done [Figure 2(a)] and further checked for occlusal interference. Following coronal build-up, the cast was duplicated by using polyvinyl siloxane putty impression material (Aquasil Soft Putty, Dentsply) [Figure 2(b)]. The index should cover the whole palatal surface of tooth to be restored, extending over the labial side of tooth surface and should extend at least two teeth on either side of the tooth to be restored. Labial surface of the putty template was removed up to middle third of the crown, to aid in the reconstruction of the lost tooth structure. A clinical try-in of the fabricated putty index was done on the patient's teeth to ensure adequate fit and extensions [Figure 2(c)]. Following isolation, 45-degree deep bevelling was done on both incisors to remove the unsupported enamel and increase the surface area. Selective etching of teeth was done for 30 seconds with a 37\% phosphoric acid gel (Magic ACID, Coltene), rinsed for 30 seconds and dried with air spray followed by application of dentin bonding agent (One Coat Bond SL, Coltene), which was light-cured for 40 seconds buccally and 40 seconds palatally by using a LED light-curing equipment (Coltolux LED, Coltene) having an intensity of $1400 \mathrm{~mW} / \mathrm{cm}^{2}$. The restoration was initiated with a small amount of the selected shade of composite (SwissTec Composite, Coltene 
Whaledent) applied in the portion corresponding to the palatal aspect in the silicone matrix extending upto the incisal edge. Then the resin in silicone index was adapted intraorally on the palatal surface of the teeth and polymerised. The index was removed, and palatal scaffold was created [Figure 2(d)]. The same resin was used to create marginal enamel walls of the restorations by using Mylar strip. Labial surface was then restored by incremental build-up. After polymerisation of the last layer, the surface was cleaned with water spray and dried with air spray. Marginal adaptations and removal of excessive resins were done by fine grit diamond points, a fine-grained composite polishing disk (Soflex, 3M, Japan) and interface sandpapers (Epitex, GC, Japan). Post-operative photograph [Figure 3(a)] and radiograph [Figure 3(b)] were then recorded.

The patient was informed about the oral hygiene maintenance and was kept under follow-up till 6 months.

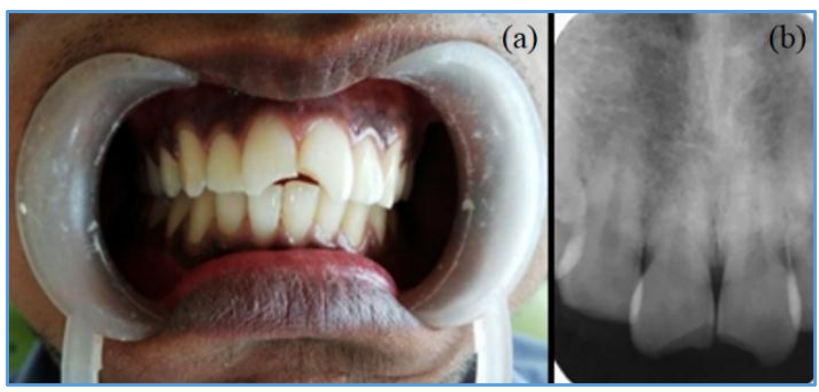

Figure 1. (a) Pre-operative Clinical Photograph, (b) Pre-operative Radiograph

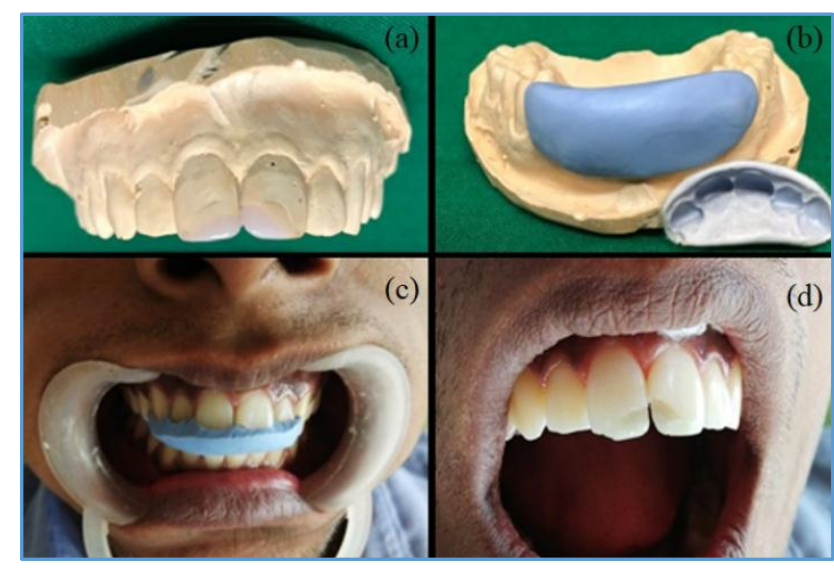

Figure 2. (a) Direct composite mock-up on Gypsum Model, (b) Silicone Matrix to guide the Restoration, (c) Clinical try-in of Putty Index, (d) Palatal Scaffold preparation using Putty Index

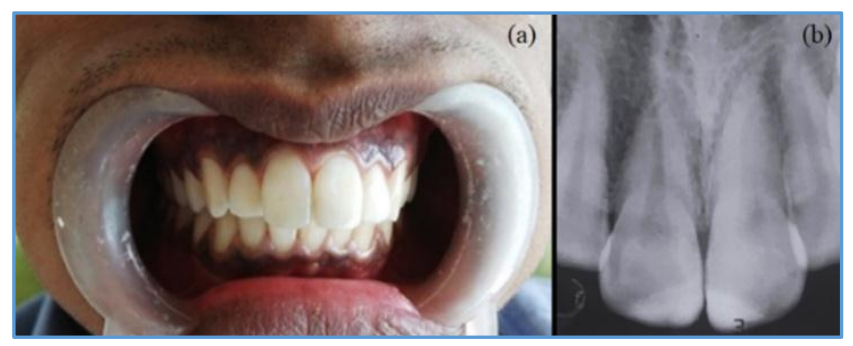

Figure 3. (a) Post-operative Clinical Photograph, (b) Post-operative Radiograph

\section{DISCUSSION}

Traumatic injuries involving maxillary central incisors cause a significant impact on the quality of life in terms of physical and psychological discomfort and have the potential to negatively affect social relationships. Management of the same provides great challenge to the clinicians, both from a functional and an aesthetic perspective. There are various treatment modalities for management of coronal tooth fractures such as fixed prosthesis, composite restoration, reattachment of the fracture fragment (if available) with or without additional retentions. Failure to preserve the fractured fragment guides the treatment for a reconstruction with direct composite resin. Among the different techniques considered to restore the tooth with composite restoration, Index Technique using silicone putty index has proved to be simple yet effective method of obtaining dental contours and convexities, which would be more laboured and lengthier in a direct free-hand composite restorations or indirect restorative technique using preformed crowns/thermoplastic moulds. ${ }^{10}$

The choice of resin composite should be focused on aspects related to the strength and aesthetics. The present hybrid resins, due to its high percentage of inorganic filler and diversity of colours result in longer lasting restorations and allow satisfactory clinical results. ${ }^{11}$ In the present case, the patient was very satisfied with the durability, aesthetic outlook and especially the colour harmony and gloss of the restorations.

Since years, the anterior direct resin restorations have been compared to the indirect full coverage crowns and veneers and are considered as a weak contender, especially with respect to durability and colour resistance though indirect restoration tends to sacrifice the healthy tooth structure and challenges the clinician to match with the adjacent un-restored teeth. It should be kept in mind that like all dental procedures, direct composite resin restorations have some indications and contraindications. In this regard, case selection in respect to location and aspect of the fracture combined with a balanced occlusion may act as the key to clinical success. If proper occlusal relations are maintained correct shade selection, good isolation, good adhesion and detailed polishing are performed, quality materials and improved techniques are used, together with clinical expertise direct composite resin restorations can do wonder and the success rate of these restorations would definitely increase. ${ }^{12}$

\section{CONCLUSION}

Restoring a fractured anterior tooth being a complex procedure, restorative procedures should be planned and executed with attention to dental contours and convexities, facilitating the re-establishment of function and aesthetics. In this perspective, the 'Index Technique' definitely proves to be simple yet effective that will fulfil all the requirements of dental personnel. Hereby, dental professionals can conveniently opt for direct restorations with composite resins, which are obviously one of the best treatment options for today's dentistry.

\section{REFERENCES}

[1] Andreasen JO, Andreasen F, Andersson L. Textbook and color atlas of traumatic injuries to the teeth. $3^{\text {rd }}$ edn. St. Louis, MO: Mosby 1994. 
[2] Reis A, Loguercio AD, Kraul A, et al. Reattachment of fractured teeth: a review of literature regarding techniques and materials. Oper Dent 2004;29(2):22633.

[3] Arnaout MA. A conservative approach towards the restoration of coronal fracture in anterior teeth. J Res Dent 2014;2(2):92-5.

[4] Terry DA, Leinfelder KF. An integration of composite resin with natural tooth structure: the class IV restoration. Pract Proced Aesthet Dent 2004;16(3):235-42.

[5] Olsburgh S, Jacoby T, Krejci I. Crown fractures in the permanent dentition: pulpal and restorative considerations. Dent Traumatol 2002;18(3):103-15.

[6] Reis A, Francci C, Loguercio AD, et al. Re-attachment of anterior fractured teeth: fracture strength using different techniques. Oper Dent 2001;26(3):287-94.

[7] Andreasen FM, Norén JG, Andreasen JO, et al. Long term survival of fragment bonding in the treatment of fractured crowns: a multicentre clinical study. Quintessence Int 1995;26(10):669-81.
[8] Lavigueur C, Zhu XX. Recent advances in the development of dental composite resins. RSC Adv 2012;2:59-63.

[9] Fellippe LA, Monteiro S Jr, De Andrada CA, et al. Clinical strategies for success in proximoincisal composite restorations. Part II. Composite application technique. J Esthet Restor Dent 2005;17(1):11-21.

[10] Rajavardhan K, Sai Sankar AJ, Shaik TA, et al. A novel technique in restoring fractured anterior teeth. J Clin Diagn Res 2014;8(2):244-5.

[11] Sakai VT, Anzai A, Silva SMB, et al. Predictable esthetic treatment of fractured anterior teeth: a clinical report. Dent Traumatol 2007;23(6):371-5.

[12] Bora K. Emulating natural morphology in anterior crown fractures: two years follow-up report. Adv Dent \& Oral Health 2017;6(1):1-5. 